\title{
The etiology of occupational pulmonary aluminosis - the past and the present
}

\author{
Petra Smolkova ${ }^{a}$, Marie Nakladalova ${ }^{a}$
}

\begin{abstract}
Background. The authors review pulmonary aluminosis caused by exposure to dust containing aluminium and its compounds, mainly oxides. Special attention is paid to various factors of occupational exposure as to an important etiologic issue. The condition has a rich and interesting history dating back to the 1930s. The most significant occupational exposures are associated with processes in bauxite smelting, the use of fine aluminium powder, exposure to aluminium welding fumes, grinding and polishing of aluminium materials.

Methods and Results. A literature search for relevant scientific studies in English was performed using the following internet databases: relevant sections of The Cochrane Library, EBSCO Discovery Service, Ovid, ProQuest Science Journals, PubMed, ScienceDirect, Scopus and Web of Knowledge. The initial clinical manifestations of pulmonary aluminosis are exertional dyspnea with dry, non-productive cough. Depending on the type and length of the occupational exposure, ventilatory defects may vary considerably from restrictive to obstructive pattern. Radiographic findings commonly showing nodular or slightly irregular opacities are predominantly located in the upper, less frequently in the lower lung fields, or can have a diffuse pattern. In advanced stages, severe pulmonary fibrosis with honeycombing occured. Conclusions. Although pulmonary aluminosis is a very rare disease, it still occurs. Since the industrial importance and use of aluminium continue to rise, lung damage from exposure to respirable aluminium particles should not be overlooked but monitored and prevented. Even today, the pathophysiology of pulmonary aluminosis has not been explained as yet.
\end{abstract}

Key words: pulmonary aluminosis, aluminium and its compounds, pneumoconiosis

Received: November 11, 2013; Accepted: March 28, 2014; Available online: April 29, 2014

http://dx.doi.org/10.5507/bp.2014.017

${ }^{a}$ Department of Occupational Medicine, Faculty of Medicine and Dentistry, Palacky University Olomouc, Czech Republic Corresponding author: Petra Smolkova, e-mail: smolkova.p@gmail.com

\section{INTRODUCTION}

As early as in 1936, the effect of aluminium-containing dust inhalation on human health was studied in Great Britain. At that time, however, no relationship with pulmonary fibrosis was found ${ }^{1}$. Currently, there is no doubt about the existence of lung damage from inhalation exposure to dust containing aluminium particles or compounds. Pulmonary aluminosis is defined as pneumoconiosis caused by the presence of dust containing aluminium in the lung tissue ${ }^{2}$. The condition is clinically and prognostically significant in that it may result in pulmonary fibrosis including all its consequences. There were reports of cases of death even after few years from the onset of symptoms, e.g. after 3 or 5 years ${ }^{3,4}$.

As in other pneumoconioses, there is no effective causal therapy for aluminosis.

This review article aims at drawing attention to and summarizing information on pulmonary aluminosis as a rare work-related damage to the lung parenchyma of the pneumoconiosis type caused by exposure to dust containing aluminium and its compounds. The review also focuses on various factors of occupational exposure.

\section{REVIEW OF KNOWLEDGE ON PULMONARY ALUMINOSIS, ESSENTIAL STUDIES}

The first cases of lung damage from work-related exposure during aluminium processing were reported in the 1930s in Germany. In 1934, Baader reported the first case ever of pulmonary fibrosis associated with the above exposure, as mentioned in a 1938 study by Doese ${ }^{5}$. In the 1940s, damage to the lungs from aluminium-containing dust inhalation was studied by Goralewski who first used the term "aluminium lung" ${ }^{\circ}$. In his work, he discussed several pathophysiological mechanisms. He admitted that other environmental factors and mixed exposures may contribute to the etiology of the condition. However, he had no doubts that dust containing aluminium may cause severe progressive lung disease. For example, he found signs of pulmonary aluminosis in $26 \%$ of 628 workers from 6 plants producing aluminium powder for ammunition; his patients presented with cough, dyspnea, rather reticular opacities in the apex or middle lung fields and pulmonary fibrosis ${ }^{5,7}$. He considered the use of stearic acid as an additive in aluminium powder production as safer than e. g. the use of mineral oil, with this opinion being supported by other experts in the following decades ${ }^{7,8}$.

Also in the 1940s, thirty-five cases of pulmonary fibrosis were reported among 344 Canadian aluminium potroom workers with exposure in the manufacture of 
alumina abrasives by Shaver and Riddel. Of those, ten died due to respiratory failure ${ }^{4}$. Moreover, Koelsch (in 1960) reported that between 1943 and 1960, twenty-seven cases of pulmonary aluminosis were recognized and compensated in Germany ${ }^{9}$.

Generally, over the past years, pulmonary diseases caused by occupational exposure to aluminium and its compounds have been gradually reported in association with the following diagnoses: pulmonary fibrosis (aluminosis), asthma, alveolar proteinosis, lung cancer, granulomatosis, chronic bronchitis, acute tracheobronchitis and pneumonitis ${ }^{10-14}$. Among these diseases pulmonary fiborosis has been the most frequently discussed disorder.

The initial clinical manifestations of pulmonary aluminosis are exertional dyspnea with dry, non-productive cough $^{6,12,15-19}$. Crepitation is also reported ${ }^{16}$. Restrictive ventilatory defects are observed, sometimes accompanied by decreased diffusing capacity ${ }^{12,15,18,20}$. On the other hand, Townsend et al. reported a relationship of impaired lung function to a higher prevalence of small opacities and a decrease in $\mathrm{FEV}_{1}$ in workers with increasing duration and cumulative total dust exposure (in one study exposure of 20 or more years) (ref. ${ }^{21,22}$ ). A clear obstructive pattern of pulmonary ventilation parameters was repeatedly found in aluminium potroom workers ${ }^{20,23-25}$. Radiographic findings may vary considerably, showing nodular or slightly irregular opacities that may merge into more prominent formations, most frequently in the upper lung fields ${ }^{15,16,21,26}$. Some authors also reported their distribution in the lower lung fields or, less frequently, a diffuse pattern ${ }^{4,14,21,26}$. Possible mediastinal enlargement was also mentioned by some authors ${ }^{27}$. Later, subpleural bullous emphysema is frequent, potentially complicated by spontaneous pneumothorax, with recent studies suggesting possible association with higher serum aluminium levels ${ }^{6,12,28,29}$. In advanced stages, severe pulmonary fibrosis with honeycombing was described ${ }^{8,12,14,16,30-32}$.

Traditionally, the highest risk with respect to potential lung damage is reported to be associated with processes in bauxite smelting, the use of fine aluminium powder in the manufacture of explosives and, last but not least, exposure to aluminium welding fumes, as shown in more recent case reports ${ }^{33-37}$. Some studies reported occasional cases of aluminosis from grinding and polishing of aluminium materials ${ }^{12,17,28}$. The authors of this review dealt with a case of pulmonary aluminosis in an aluminium polisher whose disease was aknowledged as an occupational one.

In 1986, De Vuyst and colleagues published a case of a metal polisher doing his job for 24 years, using abrasives to polish aluminium materials mainly in the second half of his exposure ${ }^{17}$. He worked in a high concentration of aluminium dust. At the age of 51 years, he developed the first symptoms in the form of exertional dyspnea and nonproductive cough, and within 5 years, he could not do his job any longer. Another five years later, he was diagnosed with lung adenocarcinoma that progressed, causing the patient's death in the same year. It must be noted, however, that he was a heavy smoker. Apart from prominent opacity in the right upper lung field due to tumor, a chest radiograph showed numerous interstitial infiltrates that were predominant in the mid lung fields, hilar enlargement, and honeycombing and emphysema in the bases. There was mild restriction of pulmonary function and marked reduction in transfer factor. Analysis of mineral particles in the lung tissue, bronchoalveoalar lavage, and lymph nodes revealed that most foreign particles present were of metallic aluminium (their size was $0.5 \mu \mathrm{m}-$ $5 \mu \mathrm{m})$. An important role in the extensive deposition of aluminium material in the worker's lungs was very likely played by his massive exposure to dust.

The pathophysiological basis of aluminosis was discussed, for instance, by Gilks and Churg in 1987 (ref. ${ }^{4}$ ). The authors used a case report of an aluminium smelting industry worker to ask what is behind the ability of aluminium to cause lung tissue fibrosis. In the patient's autopsy material, they found huge amounts of both nonfibrous and fibrous particles of aluminium, namely alpha aluminium oxide $\left(\mathrm{Al}_{2} \mathrm{O}_{3}\right)$. Logically, this finding subsequently led to a question whether fibrous aluminium particles are responsible for the fibrogenicity. However, the question still remains unanswered. They suggested that the rare incidence of aluminosis may be caused by rare and poorly studied presence of aluminium and its oxides in the form of fibers.

It is aluminium oxide used in the production of and work with abrasives that is often reported to be associated with fibrogenicity in lung tissue. Jederlinic et al. presented a series of cases of workers engaged in the production of grinding wheels and tools using aluminium oxide ${ }^{26}$. From one thousand workers in that plant examined in the study, three were diagnosed with severe, histologically confirmed pulmonary fibrosis, and another six with abnormalities suggestive of interstitial processes. According to the authors, this prevalence was 300 -fold that of idiopathic pulmonary fibrosis. Although mixed dust exposure could not be completely excluded, dust containing aluminium oxide was the most likely cause. There were more studies documenting the dangers of exposure to aluminium oxide published in the past. As early as in the 1940s, Shaver and Riddel described signs of interstitial fibrosis in approximately $10 \%$ of workers exposed to aluminium oxide ${ }^{4,12}$. In the 1980s, Wegman and Eisen reported an increase in both non-malignant and malignant diseases in a plant producing abrasives from aluminium oxide. The authors used data from death certificates and employment records ${ }^{38}$. Townsend et al. studied the risks of dust exposure in a company refining bauxite to produce aluminium. In $7-8 \%$ of 788 workers in the cohort, irregular opacities mainly in the lower lung fields were detected, together with a moderate increase in the prevalence of opacities associated with high cumulative exposure in non-smokers. Smokers then had a significantly higher prevalence of opacities ${ }^{21}$.

There have been extensive discussions in the literature regarding one of aluminium oxide low temperature range transitional forms, gamma aluminium oxide, occurring at temperatures between $250{ }^{\circ} \mathrm{C}$ and $500{ }^{\circ} \mathrm{C}$ ( ref. $^{21}$ ). As early as in the $1950 \mathrm{~s}$, a hypothesis was formulated based on animal tests that gamma aluminium oxide is responsible 
for the development of pulmonary aluminosis ${ }^{4}$. Most of the later studies, however, came to the conclusion that gamma aluminium oxide is not the only noxious substance causing pulmonary aluminosis, not even in plants where it is known to be present ${ }^{21}$.

In their aforementioned study, Gilks and Churg stressed the fact that X-ray diffraction had demonstrated only alpha but not gamma aluminium oxide or metal aluminium in autopsy material. The authors concluded that the previous suggestions relating aluminium-induced fibrosis to the presence of gamma aluminium oxide had not been correct ${ }^{4}$.

Similarly, Jederlinic et al. raised doubts over the discussed fibrogenic capacity of gamma aluminium oxide as this low temperature range transitional form of aluminium oxide is destroyed by high temperatures used in foundry industry (approximately $960{ }^{\circ} \mathrm{C}$ ) ( ref. $^{26,39,40}$ ).

According to Townsend et al., another problem is the fact that even in plants known for the presence of low temperature range transitional forms of aluminium oxide such as bauxite refineries, it is impossible to either accurately determine the amounts of these forms or select workers with pure exposure to them. Therefore, the authors consider specific effects of exposure to these forms of aluminium oxide as speculative, which is even true for the cohort in their study ${ }^{21}$.

Another contribution to the discussion on the principles of aluminium pathogenicity in the lung tissue is a 1987 study by Dinman ${ }^{7}$. It provided a detailed analysis of the impact of processing aluminium powder, namely the role of additives and lubricants, already discussed in earlier studies. He documented that pulmonary aluminosis cases associated with production of aluminium powder in the past had been caused by the use of non-polar aliphatic oils as lubricants, but never by the traditional use of polar derivatives of stearic acid. Thus, the common denominators of hazardous exposure were exposure to very fine respirable aluminium dust with a large total surface area and the use of lubricants easily removable in biological systems. Between exposed reactive surfaces of aluminium particles and macrophages, these properties allowed intracellular oxidative processes leading to overproduction of oxygen free radicals and subsequent damage, with the pro-oxidative property of aluminium being confirmed by more recent studies as well ${ }^{41}$. According to the author, this hypothesis is supported by the fact that well documented cases of pulmonary aluminosis were associated with periods when the non-polar lubricants were used in specific regions, such as Germany in 1938 to 1945 and Great Britain in 1950 to 1957 (ref. $^{7}$ ).

More recently, Kraus et al. in their 2006 article reported lung changes in workers in two German plants producing aluminium powder who had been exposed to a mixture of aluminium particles and various lubricants. The changes were detected by HRCT in 15 out of 62 workers, including 2 polishers ${ }^{28}$. These changes included small rounded opacities up to $3 \mathrm{~mm}$ mainly in the upper and in four cases also in the middle lung regions. There were also signs of a thickening of the interlobular septae in three cases. Patients with aluminium-induced HRCT findings had higher concenrations of aluminium in plasma and urine. They had lower vital capacity as well. According to the results of the study smoking had no influence on the prevalence of CT changes ${ }^{28}$.

\section{CONCLUSION}

Pulmonary aluminosis is defined as pneumoconiosis caused by the presence of dust containing aluminium in the lung tissue and may result in pulmonary fibrosis. It is caused by the exposure to aluminium and its compounds under diverse occupational circumstances and factors. An important and dangerous role is said to be played by inhalation of fine dust with respirable aluminium particles sized $0.5-5 \mu \mathrm{m}^{16}$. Particular manufacturing technologies using aluminium and its compounds have been found to be crucial. And, last but not least, the level of exposure is logically an important factor, with aluminium particles being significantly persistent in the organism ${ }^{42}$.

However, even today, the exact pathogenesis of aluminium-induced diseases of the lung parenchyma is unknown, although some more recent sources pointed to a potential contribution of individual genetic determinants increasing the risk of their development, as shown, for instance, in beryllium, suggesting a possible direction for future research ${ }^{11}$.

Although pulmonary aluminosis is a very rare disease, it still occurs. Since the industrial importance and use of aluminium continue to rise, lung damage from exposure to respirable aluminium particles should not be overlooked but monitored and prevented. Naturally, it is desirable to try to detect early stages of the disease using modern methods such as HRCT of the lungs, as recommended mainly by more recent studies ${ }^{28}$. Also valuable may be exposed workers' blood and urine aluminium concentration tests.

\section{ABBREVIATIONS}

$\mathrm{FEV}_{1}$, forced expiratory volume in 1 second; HRCT, high-resolution computed tomography.

\section{ACKNOWLEDGEMENT}

Supported by the internal grant of Palacky University Olomouc No. LF_2013_009.

Authorship contributions: P.S., M.N.: Literature search; P.S.: Conception and manuscript writing; M.N.: Final approval.

Conflict of interest statement: The authors state that there are no conflicts of interest regarding the publication of this article. 


\section{REFERENCES}

1. Hunter D, Milton R, Perry KMA, Thompson DR. Effect of aluminium and alumina on the lung in grinders of duramin aeroplane propellers. Br J Ind Med 1944;1:159-64.

2. Dorland WA. Dorland's pocket medical dictionary. 28th ed. Philadelphia: Elsevier Saunders; 2009.

3. Ueda M, Mizoi Y, Maki Z, Maeda R, Takada R. A case of aluminum dust lung: A necropsy report. Kobe J Med Sci 1958;4:91-9.

4. Gilks B, Churg A. Aluminum-induced pulmonary fibrosis: Do fibres play a role? Am Rev Respir Dis 1987;136:176-9.

5. Doese M. Industrial medicine studies on injury to health caused by aluminium, in particular lung disease from aluminium dust. Arch Gewerbepathol 1938;8:501-31

6. Goralewski G. The aluminium lung: A new industrial disease (Abstract of Goralewski, 1947). Br J Ind Med 1948;6:53-4.

7. Dinman BD. Aluminum in the lung: The pyropowder conundrum. $J$ Occup Med 1987;29:869-76.

8. McLaughlin AIG, Kazantzis G, King E, Teare D, Porter RJ, Owen R Pulmonary fibrosis and encephalopathy associated with the inhalation of aluminium dust. Br J Ind Med 1962;19:253-63.

9. Koelsch, F. Pulmonary disease caused by aluminum dust. Beitr Klin Tuberk 1942;97:688-93. 1960 - Private communication, cited by Mitchell et al.

10. Kongerud J, Samuelsen SO. A longitudinal study of respiratory symptoms in aluminum potroom workers. Am Rev Respir Dis 1991;144:10

11. Kelleher P, Pacheco K, Newman LS. Inorganic dust pneumonias: the metal-related parenchymal disorders. Environ Health Persp 2000;108(Suppl.4):685-96.

12. Krewski D, Yokel R, Nieboer E, Borchelt D, Cohen J, Harry J, Kacew S, Lindsay J, Mahfouz AM, Rondeau V. Human health risk assessment for aluminium, aluminium oxide, and aluminium hydroxide. J Toxicol Environ Health 2007;Part B 10(S1):1-269.

13. Miller RR, Churg AM, Hutcheon M, Lam S. Pulmonary alveolar proteinosis and aluminum dust exposure. Am Rev Respir Dis 1984;130:312-5.

14. Chen WJ, Monnat RJ, Chen M, Mottet K. Aluminum induced pulmonary granulomatosis. Hum Pathol 1978;9:705-11.

15. Parkers RW. Occupational lung disorders. 3rd ed. Oxford: Butterworth-Heinemann Ltd; 1994.

16. Guidotti TL. Pulmonary aluminosis - a review. Toxicol Pathol 1975;3(16):16-8.

17. De Vuyst $P$, Dumortier P, Rickaert F, Van de Weyer R, Lenclud C, Yernault JC. Occupational lung fibrosis in an aluminium polisher. Eur J Respir Dis 1986;68:131-40.

18. Jordan JW. Pulmonary fibrosis in a worker using an aluminium powder. Brit J Industr Med 1961;18:21-3.

19. Fraser RS, Pare JA. Synopsis of diseases of the chest. 2nd ed. Philadelphia:W. B. Saunders Company; 1993.

20. Abramson MJ, Wlodarczyk JH, Saunders NA, Hensley MJ. Does aluminum smelting cause lung disease? Am Rev Respir Dis 1989;139:104257.

21. Townsend MC, Sussman NB, Enterline PE, Morgan WKC, Belk HD Dinman BD. Radiographic abnormalities in relation to total dust exposure at a bauxite refinery and alumina-based chemical products plant. Am Rev Respir Dis 1988;138:90-5.

22. Townsend MC, Enterline PE, Sussman NB, Bonney TB, Rippey LL. Pulmonary function in relation to total dust exposure at a bauxite refinery and alumina-based chemical productsplant. Am Rev Respir Dis 1985;132(6):1174-80.
23. Field GB. Pulmonary function in aluminium smelters. Thorax 1984;39:743-51.

24. Larsson K, Eklund A, Arns R, Lowgren H, Nystrom J, Sundstrom G, Tornling $\mathrm{G}$. Lung function and brochial reactivity in aluminum potroom workers. Scand J Work Environ Health 1989;15(4):296-301.

25. Musk AW, de Klerk NH, Beach JR, Fritschi L, Sim MR, Benke G, Abramson M, McNeil JJ. Respiratory symptoms and lung fuction in alumina refinery employees. Occup Environ Med 2000;57:279-83.

26. Jederlinic PJ, Abraham JL, Churg A, Himmelstein JS, Epler GR, Gaensler EA. Pulmonary fibrosis in aluminum oxide workers. Am Rev Respir Dis 1990;142:1179-84.

27. Ansell G. Imaging drug reactions and toxic hazards. 3rd ed. London: Hodder Arnold; 1998

28. Kraus T, Schaller KH, Angerer J, Hilgers RD, Letzel S. Aluminosis detection of an almost forgotten disease with HRCT. J Occup Med Tox [serial on the Internet]. 2006 Feb [cited 2013 Aug 16];1(4):[about 9 p.]. Available from: http://www.occup-med.com/content/1/1/4

29. Han S, Yazkan R, Kocer B, Gülbahar G, Köse SK, Dural K, Sakinci Ü. Are serum aluminum levels a risk factor in the appearance of spontaneous pneumothorax? Turk J Med Sci 2010;40(3):459-63.

30. Meyer FA, Kasper W. Examination of the effects of aluminium on the lung. Dtsch Arch Klin Med 1942;189:471-95.

31. Edling NPG. Aluminum pneumoconiosis: A roentgendiagnostic study of five cases. Acta Radiol 1961;56:170-8.

32. Mitchell J, Manning GB, Molyneux M, Lane RE. Pulmonary fibrosis in workers exposed to finely powdered aluminium. Br J Ind Med 1961;18:10-23.

33. Ansari HA, Al-Bahrani G, Vishwanath M, Prescott M, James J. Thoracic scintigraphy in aluminosis. Lymph node uptake on bone scan. Clin Nucl Med 2009;34(1):24-6.

34. Fireman E, Goshen M, Ganor E, Spirer Z, Lerman Y. Induced sputum as an additional tool in the identification of metal-induced sarcoidlike reaction. Sarcoidosis Vasc Dif 2004;21(2):152-6.

35. Chelvanathan A, Drost N, Cutz JC. Desquamative interstitial pneumonia in an aluminum welder: a case report. Chest 2011;140(4 MeetingAbstracts):129A

36. Hull MJ, Abraham JL. Aluminum welding fume-induced pneumoconiosis. Hum Pathol 2002;33(8):819-25.

37. Balkissoon R. A 26-year-old welder with severe non-reversible obstructive lung disease. COPD 2006;3:63-7.

38. Wegman DH, Eisen EA. Causes of death among employees of a synthetic abrasive product manufacturing company. J Med 1981;23:748-54.

39. Frazer EJ, Thonstad J. Alumina solubility and diffusion coefficient of the dissolved alumina species in low-temperature fluoride electrolytes. Metall Mater Trans B 2010;41B:543-8.

40. Kostić E, Kiss Š, Bošković S, Zec S. Mechanical activation of the gamma to alpha transition in $\mathrm{Al}_{2} \mathrm{O}_{3}$. Powder Techol 1997;91:49-54.

41. Zatta P, Kiss T, Suwalsky M, Berthon G. Aluminium(III) as a promoter of cellular oxidation. Coordin Chem Rev 2002;228:271-84.

42. Voisin C, Fisekci F, Buclez B, Didier A, Couste B, Bastien F, Brochard $P$, Pairon JC. Mineralogical analysis of the respiratory tract in aluminium oxide-exposed workers. Eur Respir J 1996;9:1874-9. 